\title{
Molecular biological characteristics of foot-and-mouth disease virus in the African buffalo in southern Africa
}

\author{
Authors: \\ Christopher J. Kasanga \\ Rahana Dwarka ${ }^{2}$ \\ Gaothlele Thobokwe ${ }^{3}$ \\ Jemma Wadsworth ${ }^{4}$ \\ Nick J. Knowles ${ }^{4}$ \\ Misheck Mulumba ${ }^{5}$ \\ Ezekia Ranga ${ }^{6}$ \\ Jimis Deve ${ }^{11}$ \\ Cornelius Mundia ${ }^{10}$ \\ Patrick Chikungwa \\ Laureta Joao ${ }^{9}$ \\ Raphael Sallu \\ Mmeta Yongolo \\ Philemon N. Wambura \\ Mark M. Rweyemamu \\ Donald P. King \\ Affiliations: \\ ${ }^{1}$ Southern African Centre \\ for Infectious Diseases \\ Surveillance, Sokoine \\ University of Agriculture, \\ Tanzania \\ ${ }^{2}$ Onderstepoort Veterinary \\ Institute, University of \\ Pretoria, South Africa \\ ${ }^{3}$ Botswana Vaccine Institute, \\ Botswana \\ ${ }^{4}$ WRLFMD, The Pirbright \\ Institute, United Kingdom \\ ${ }^{5}$ Southern African \\ Development Community \\ Secretariat, Botswana \\ ${ }^{6}$ Ministry of Livestock \\ Development and Fisheries, \\ Tanzania \\ ${ }^{7}$ Tanzania Veterinary \\ Laboratory Agency, Tanzania \\ ${ }^{8}$ Southern African \\ Development Community, \\ Transboundary Animal \\ Diseases Section, Malawi \\ ${ }^{9}$ Southern African \\ Development Community, \\ Transboundary Animal \\ Diseases Section, Angola \\ ${ }^{10}$ Southern African \\ Development Community, \\ Transboundary Animal \\ Diseases Section, Zambia \\ ${ }^{11}$ Southern African \\ Development Community, \\ Transboundary Animal \\ Diseases Section, Mozambique \\ Read online: \\ Scan this $Q R$ \\ code with your \\ smart phone or \\ mobile device \\ to read online.
}

Foot-and-mouth disease (FMD) is endemic in most countries in southern Africa. African buffaloes (Syncerus caffer) are known to play a significant role in the transmission and dynamics of FMD virus (FMDV) in wildlife-livestock interface areas. The aim of this study was to investigate the serotype and determine the genetic relationships of FMDV recovered from animals in Tanzania, Zambia and Mozambique, and compare them with viruses detected from elsewhere in the subSaharan region. A total of 150 oesophageal-pharyngeal (probang) samples collected in 2010 from cattle and buffaloes in Marromeu (Mozambique), Katavi (Tanzania) and Lochninvar (Zambia) National Parks were used in this study. The presence of FMDV was determined by laboratory methods such as VI, antigen ELISA and real-time RT-PCR. Phylogenies of VP1 sequences were determined by the neighbour-joining method. The overall FMDV genome detection rate was $6.7 \%(n=10)$, with SAT 1 being the most frequent serotype $(60 \% ; n=6)$ isolated in cattle and buffaloes in Mozambique, Tanzania and Zambia followed by SAT $3(30 \% ; n=3)$ and SAT $2(10 \% ; n=1)$. Genotyping showed that type SAT 1 viruses fell into either the TOPOTYPE 1 (NWZ) or UNASSIGNED topotypes, type SAT 2 into the AFRICA topotype I and type SAT 3s into topotype IV (SEZ). This study reveals that serotypes SAT 1-3 are maintained in cattle and buffaloes in livestock-wildlife interface areas in Marromeu, Katavi, and Lochinvar National Parks. Phylogenetic analysis of FMDV isolates from Tanzania, Zambia and Mozambique showed that they are genetically related to lineages and topotypes from Africa. This information contributes to the understanding of the epidemiology of FMD in southern Africa. In Mozambique, Tanzania and Zambia, lack of consistent surveillance systems and animal movement controls make it difficult to determine the exact source of FMD and transmission dynamics of FMDV. Further studies are needed to elucidate the complex epidemiology of FMD in Africa.

\section{Acknowledgements}

This work was supported by the Wellcome Trust Grant WT087546MA to the Southern African Centre for Infectious Diseases \& Surveillance (SACIDS).

\author{
Correspondence to: Christopher Kasanga \\ Email: christopher.kasanga@sacids.org \\ Postal address: PO Box 3019, Chuo Kikuu, Morogoro, Tanzania \\ How to cite this article: Kasanga, C.J., Dwarka, R., Thobokwe, G., Wadsworth, J., Knowles, N.J., Mulumba, M. et al., 2014, 'Molecular \\ biological characteristics of foot-and-mouth disease virus in the African buffalo in southern Africa', Onderstepoort Journal of Veterinary \\ Research 81(2), Art. \#728, 1 page. http://dx.doi.org/10.4102/ojvr.v81i2.728 \\ Note: Proceedings of the 2 nd One Health Conference in Africa. Jointly organised by the Southern African Centre for Infectious Disease \\ Surveillance and the Tanzania National Institute for Medical Research, held at the Snow Crest Hotel in Arusha, Tanzania from 16th to 19th \\ April 2013: http://www.sacids.org/kms/frontend/index.php?m=119. \\ Copyright: @ 2014. The Authors. Licensee: AOSIS OpenJournals. This work is licensed under the Creative Commons Attribution License.
}

